\title{
KAJIAN DETOKSIFIKASI ASAM SIANIDA PADA KETELA POHON (Manihot esculenta Crantz) MELALUI PEMETIKAN PUCUK BATANG
}

\author{
T. G. Belawa Yadnya dan A. A. A. S. Trisnadewi \\ Fakultas Peternakan, Universitas Udayana \\ e-mail: belawayadnya_fapet@yahoo.com
}

\begin{abstract}
ABSTRAK
Penelitian bertujuan untuk mengatahui pengaruh pemetikan pucuk batang terhadap detoksifikasi asam sianida pada ketela pohon. Penelitian menggunakan rancangan acak lengkap (RAL) dengan empat perlakuan yaitu ketela pohon tanpa dipetik pucuk batang (A), ketela pohon dipetik pucuk batang setiap 2 minggu (B), ketela pohon dipetik pucuk batang setiap 3 minggu (C), dan ketela pohon dipetik pucuk batang setiap 4 minggu. Variabel yang diamati kadar HCN pada daun, isi umbi dan kulit, dan kadar pati pada daun, isi umbi dan kulit ubi ketela pohon. Hasil penelitian menunjukkan bahwa pemetikan setiap 2, 3, dan 4 minggu terjadi penurunan kadar $\mathrm{HCN}$ secara nyata $(\mathrm{P}<0,05)$. Hal yang sama juga terjadi penurunan kadar pati pada pemetikan pucuk batang setiap 2 dan 3 minggu secara nyata $(\mathrm{P}<0,05)$, sedangkan pada pemetikan setiap 4 minggu tidak berbeda nyata $(\mathrm{P}>0,05)$ dibandingkan dengan ketela pohon yang tidak dipetik pucuk batangnya (kontrol). Dari hasil penetian dapat disimpulkan bahwa pemetikan pucuk batang dapat menurunkan kadar asam sianida dan menurunkan kadar pati, kecuali pada pemetikan setiap 4 minggu tidak berpengaruh terhadap kadar pati ketela pohon.
\end{abstract}

Kata kunci: detoksifikasi asam sianida, kadar HCN, kadar pati, ketela pohon.

\section{PENDAHULUAN}

Ketela pohon sangat cocok ditanam di Indonesia, karena budidayanya dapat ditanam dari tepi laut sampai ke pegunungan lebih kurang 1.500 meter dari permukaan laut (Alvares dan Luna, 1974). Ketela pohon merupakan tanaman umbi-umbian sebagai penghasil karbohidrat dalam bentuk pati di umbinya (Gohl, 19875), dan biosintesa karbohidrat terjadi di dalam klorofil (Wirahadikusumah, 1985). Namun ketela pohon mempunyai kelemahan dapat menghasilkan asam sianida (HCN) yang bersifat racun (toksik) alami (Winarno,1982) dan apabila asam sianida dikonsumsi oleh manusia atau ternak di atas ambang aman dapat menyebabkan keracunan atau kematian. Kandungan asam sianida pada umbi ketela pohon sangat tergantung pada jenis atau varietasnya (Rukmana, 1997). Pada Tabel 1, lebih lanjut dijelaskan bahwa yang mempunyai kadar HCN tertinggi pada ubi kayu jenis Mangi (di tanah kurus kering) sebesar $289 \mathrm{mg} / \mathrm{kg}$ pada umbinya dan $542 \mathrm{mg} / \mathrm{kg}$ dan yang terendah adalah jenis Mangi yang ditanam di tempat yang subur sebesar $32 \mathrm{mg} / \mathrm{kg}$ pada umbi dan daun sebesar $33 \mathrm{mg} / \mathrm{kg}$ dan $146 \mathrm{mg} / \mathrm{kg}$.

HCN dapat mematikan dengan kadar 0,5 - 3,5 $\mathrm{mg} / \mathrm{kg}$ bobot badan. Rasa manis kadar $\mathrm{HCN}<50$ $\mathrm{mg} / \mathrm{kg}$. FAO, singkong dengan kadar $50 \mathrm{mg} / \mathrm{kg}$ masih aman dikonsumsi dan pengolahan bisa masih tertinggal $10-40 \mathrm{mg} / \mathrm{kg}$ (Winarno,1982). HCN terdapat dalam senyawa linamarin dan apabila dihidrolisa atau dicerna oleh enzim akan terurai
Tabel 1. Kadar HCN pada Beberapa Jenis atau Varietas Ubi Kayu

\begin{tabular}{lccc}
\hline \multirow{2}{*}{ Jenis atau varietas } & \multirow{2}{*}{ Rasa ubi } & \multicolumn{2}{c}{ Kadar HCN (mg/kg) } \\
\cline { 3 - 4 } & & Umbi & Daun \\
\hline Mangi (di tanah subur) & Enak & 32 & 136 \\
Mangi (di tanah kurus dan kering) & Pahit & 289 & 542 \\
Betawi & Enak & 33 & 146 \\
Valenca & Enak & 39 & 158 \\
Singapura & Enak & 60 & 201 \\
Basiorao & Agak pahit & 82 & 230 \\
Bogor & Agak pahit & 90 & 324 \\
Tapikuru & Pahit & 130 & 230 \\
SPP & Pahit & 206 & 468 \\
\hline
\end{tabular}

Sumber: Rumana (1997)

menjadi glukosa, aseton dan asam sianida ( $\mathrm{HCN})$.

Murdjati (1957) telah mencoba pemanggasan daun ketela pohon sebelum dipanen, ternyata dapat menurunkan kadar HCN pada umbi ketela pohon. Berdasarkan informasi tersebut penulis ingin mencoba penelitian dengan mengubah cara pemangkasan yaitu pemangkasan dengan pemetikan pucuk batang secara frekuensi yaitu kontrol, setiap satu, dua, tiga, dan empat minggu dipetik pucuk batangnya setelah ketela pohon berumur 4 bulan sampai berumur 7 bulan. Berdasarkan uraian di atas dilakukan penelitian tentang kajian detoksifikasi asam sianida pada ketela pohon dengan pemetikan pucuk batang dengan harapan dapat mengurangi kadar $\mathrm{HCN}$, namun pada kadar pati atau produksi umbi tidak berpengaruh nyata dengan control. Selain itu petani singkong mendapatkan penghasilan tambahan dari penjualan daun singkong untuk sayur. 


\section{MATERI DAN METODE PENELITIAN}

\section{Materi}

Bahan yang dipergunakan untuk penelitian ini adalah umbi ketela pohon jenis gading yang berasal dari penelitian lapangan yang berjudul pengaruh frekuensi pemetikan pucuk batang terhadap produksi ketela pohon di Desa Guwang, Kecamatan Sukawati, Kabupaten Gianyar, Bali.

Alat-alat yang dipergunakan dalam penelitian ini meliputi neraca analitik, tabung reaksi, penangas air (water bath), labu ukur, pipet godok $25 \mathrm{ml}$, erlenmeyer,250 ml, pendingin balik, kompor, buret, dan sebagainya.

Bahan kimia yang digunakan meliputi $\mathrm{NaOH}$ (natrium hidroksida), ammonium hidroksida $\left(\mathrm{NH}_{4} \mathrm{OH}\right)$, potasium yodida $(\mathrm{KI})$, amilum, perak nitrat $\left(\mathrm{AgNO}_{3}\right)$, asam clorida $(\mathrm{HCl})$, natrium karbonat (Na2CO3), yodium kristal (Y2), tembaga sulfat $\left(\mathrm{CuSO}_{4}\right)$, asam borac $\left(\mathrm{H}_{3} \mathrm{BO}_{3}\right)$, aqadest $\left.\left(\mathrm{H}_{2}\right)\right)$, dan larutan Luff.

\section{Rancangan Penelitian}

Penelitian ini menggunakan rancangan acak lengkap (RAL) dengan empat perlakuan yaitu ketela pohon tanpa pemetikan pucuk batang (perlakuan A); ketela pohon dipetik pucuk batangnya setiap dua minggu, 3 minggu, dan empat mingu (perlakuan $\mathrm{B}$, C, dan D). Setiap perlakuan dengan lima ulangan dan setiap ulangan diambil tiga sampel.

\section{Variabel Yang Diamati}

Variabel yang diamati kadar HCN pada umbi, kulit umbi, dan daun ketela pohon dengan metode AOAC (dikutif oleh Sudarmadji et al., 1972) dan kadar pati (amilum) pada isi dan kulit ketela pohon dengan metode AOAC (dalam Sudarmadji et al., 1972).

\section{Analisis Statistika}

Data yang diperoleh kemudian ditabulasi selanjutnya diolah dengan analisis varian dan apabila terdapat perbedaan yang nyata $(\mathrm{P}<0,05)$ dilanjutkan dengan Multiple Range - Duncan's Test (Steel dan Torrie, 1989).

\section{HASIL DAN PEMBAHASAN}

\section{Pemetikan Pucuk Batang terhadap Kadar HCN pada Ketela Pohon}

Kadar HCN pada ketela pohon yang tanpa dipetik pucuk batangnya (A) adalah $64,70 \mathrm{mg} / \mathrm{kg}$ (Tabel 1). Pemetikan pucuk batang setiap; dua, tiga, dan empat minggu (B, C dan D) setelah ketela pohon berumur empat bulan berturut -turut adalah 16,73\%; 11,11\% dan $4,63 \%$ lebih rendah $(\mathrm{P}<0,05)$ dibandingkan perlakuan kontrol (A). Kadar HCN pada kulit dan daun pada ketela pohon A adalah $86,70 \mathrm{mg} / \mathrm{kg}$ dan $75,50 \mathrm{mg} / \mathrm{kg}$ (Tabel 1). Pemberiaan perlakuan B, C dan D dapat menurunkan kadar HCN secara nyata $(\mathrm{P}<0,05)$ dibandingkan dengan pemberian perlakuan kontrol (A).

Tabel 2. Pemetikan Pucuk Batang Terhadap Kadar HCN Pada Ketela Pohon

\begin{tabular}{cccc}
\hline Variabel & $\begin{array}{c}\text { Kadar HCN isi Umbi } \\
\text { Ketela Pohon (mg/ } \\
\text { kg) }\end{array}$ & $\begin{array}{c}\text { Kadar HCN kulit } \\
\text { Umbi Ketela Pohon } \\
(\mathrm{mg} / \mathrm{kg})\end{array}$ & $\begin{array}{c}\text { Kadar HCN Daun Ke- } \\
\text { tela Pohon }(\mathrm{mg} / \mathrm{kg})\end{array}$ \\
\hline A & $64,70^{\mathrm{a}}$ & $86,34^{\mathrm{a}}$ & $75,50^{\mathrm{a}}$ \\
B & $53,87^{\mathrm{d}}$ & $80,46^{\mathrm{d}}$ & $67,75^{\mathrm{d}}$ \\
C & $57,51^{\mathrm{c}}$ & $82,72^{\mathrm{c}}$ & $70,11^{\mathrm{c}}$ \\
D & $61,70^{\mathrm{b}}$ & $84,62^{\mathrm{b}}$ & $71,15^{\mathrm{b}}$ \\
\hline
\end{tabular}

Keterangan: Superskrip dengan huruf yang berbeda pada kolom yang sama berart berbeda nyata $(P<0,05)$

Pemetikan pucuk batang berarti mengurangi kesempatan klorofil untuk mensintesa karbohidrat yang nantinya akan berpengaruh terhadap hasil akhir. Pembentukan HCN sangat tergantung pada proses daripada biosintesa karhidrat di klorofil. Besarnya kadar HCN sangat tergantung pada jenis atau varietas, jenis tanah, iklim dan umur tanaman (Edwards, 1974) Kadar HCN akan berbahaya bagi kesehatan apabila senyawa linamarin terhidrolisa oleh enzim limarinase menjadi glukosa, aseton dan asam sianida. Jenis ketela pohon dalam penelitian ini adalah varietas Gading atau Valenca yang rasanya enak dan kadar HCNnya dibawah $100 \mathrm{mg} / \mathrm{kg}$ (Winarno,1982). Dari hasil penelitian ternyata semakin pendek waktu pemetikan pucuk batang maka kadar HCN semakin menurun, yang berarti pengurangan pembentukan $\mathrm{HCN}$ atau detoksifikasi pada ketela pohon dapat dilakukan dengan pemetikan pucuk batang. Penelitian ini terinspirasi yang dilakukan oleh Darjanto dan Murjati, (1959), yang menyatakan pemangkasan daun sebelum tanaman ketela pohon dipanen atau dicabut umbinya.

\section{Pemetikan Pucuk Batang terhadap Kadar Pati pada Ketela Pohon}

Pemetikan pucuk berpengaruh terhadap kadar pati pada ketela pohon tertera pada Tabel 3 .

Tabel 3. Pengaruh Pemetikan Pucuk Batang Terhadap Kadar Pati Ketela Pohon

\begin{tabular}{ccc}
\hline \multirow{2}{*}{ Perlakuan } & \multicolumn{2}{c}{ Kadar Pati (\%) } \\
\cline { 2 - 3 } & Isi Umbi & Kulit Umbi \\
\hline A & $68,06^{\mathrm{a}}$ & $40,20^{\mathrm{a}}$ \\
B & $65,23^{\mathrm{b}}$ & $35,53^{\mathrm{b}}$ \\
C & $66,10^{\mathrm{b}}$ & $38,00^{\mathrm{b}}$ \\
D & $67,61^{\mathrm{a}}$ & $40,13^{\mathrm{a}}$ \\
\hline
\end{tabular}

Keterangan: Superskrip dengan huruf yang berbeda pada kolom yang sama berarti berbeda nyata $(P<0,05)$

Pemetikan pucuk batang pada ketela pohon memperoleh hasil yaitu pada ketela pohon tanpa 
dipetik pucuk batangnya (perlakuan A) menghasilkann kadar pati pada isi dan kulit umbi adalah 68,06\% dan 40,20 \% (Tabel 3). Pemetikan pucuk batang setiap dua dan tiga minggu (perlakuan B dan C), setelah berumur empat bulan, dan setelah berumur tujuh bulan diperoleh kadar pati pada isi dan kulit umbi ketela pohon lebih rendah secara nyata $(\mathrm{P}<0,05)$, sedangkan pemetikan setiap empat minggu (perlakuan D) menghasilkan kadar pati yang lebih rendah, namun srcara statistik tidak berbeda nyata ( $\mathrm{P}>0,05)$ dibadingkan dengan ketela pohon tanpa pemetikan pucuk batang (perlakuan A).

Pemetikan pucuk batang pada perlakuan B dan $C$ dapat menurunkan kadar pati sebesar $11,62 \%$ dan, $49 \%$ secara nyata $(\mathrm{P}<0,05)$ pada kulit umbi ketela pohon, sedangkan pemetikan setiap empat minggu menghasilkan kadar pati pada kulit umbi mendekati sama dengan ketela pohon tanpa dipetik pucuk batangnya (A).

Pemetikan pucuk batang pada ketela pohon dapat menghasilkan kadar pati yang lebih rendah daripada ketela pohon yang tanpa dipetik pucuk batangnya, karena kemampuan tumbuhan untuk menghasilkan zat pati sangat tergantung dari jenis tanaman, jumlah klorofil, radiasi matahari, dan kandungan unsur hara yang terdapat pada lingkungan tanaman tumbuh dan berkembang (Edward, 1974 dan Soeharsono, 1983).

Ketela pohon termasuk tanaman $\mathrm{C}_{4}$, yang mempunyai untuk biosintesa serta kandungan stomata yang cukup banyak, sehingga semakin banyak gas $\mathrm{CO} 2$ yang dapat direduksi menjadi karbohidrat (Kusnawijaya, 1983) dengan sebagai berikut:

$$
6 \mathrm{CO} 2+\mathrm{H}_{2} \mathrm{O} \longrightarrow \mathrm{C} 6 \mathrm{H} 12 \mathrm{O} 6+6 \mathrm{O}_{2}
$$

Setelah terbentuk glukosa akan diubah menjadi polisakarida diantaranya adalah pati atau amilum dengan perubahan reaksi kimia sebagai berikut:

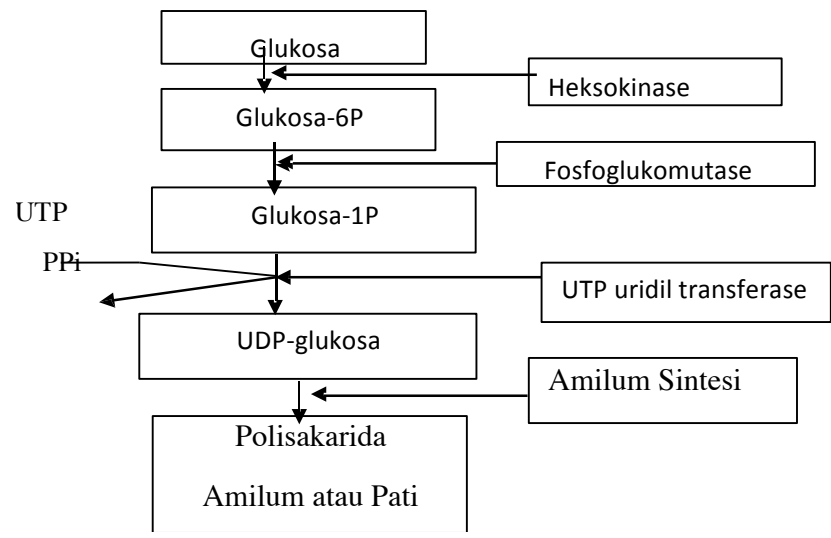

Gambar 1. Diagram Perubahan Glukosa menjadi Amilum (Wirahadikusumah, 1985)

Ketela pohon yang pucuk batangnya dipetik setiap 2 atau 3 minngu dapat menekan produksi kadar pati pada umbi ketela pohon, karena adanya pembatasan daun sebagai sumber klorofil untuk menghasilkan karbohidrat (pati), sehingga karbohidrat (pati) yang ditransfer dari daun ke umbi semakin berkurang. Namun pemetikan pucuk batang setiap 4 minggu tidak berpengaruh terhadap kadar pati pada umbi ketela pohon.

\section{SIMPULAN}

Berdasarkan hasil dan pembahasan pada penelitian ini dapat disimpulkan sebagai berikut:

1. Pemetikan pucuk batang setiap dua, tiga dan empat minggu setelah ketela pohon berumur empat bulan sangat menurunkan kadar HCN pada pada ketela pohon

2. Pemetikan pucuk batang setiap dua dan tiga minggu setelah ketela pohon berumur empat bulan dapat menurunkan kadar pati, namun pemetikan setiap empat minggu setelah ketela pohon berumur empat bulan tidak berpengaruh terhadap kadar pati pada umbi dan kulit ketela pohon.

\section{REFERENSI}

Alvares dan Luna, E., 1974. Guide for fieldcrops in the crops in the tropics tech. Asistance Barean Agency for Int. Development; 231. Co, Inc. New York. Toronto, London.

Darjanto dn Murjati, 1959. Khasiat racun dan masakan ketela pohon. Pusat Jawatan Pertanian.

Edward, D., 1974. The industrial manufacture of cassava product. An economic study tropical product institute. 56/62 Groys is roud, London.

Gohl, B. 1975. Feed information sammaries and nutritive value tropical feeds.

FAO. Feed information centre, Animal productionand Health division, Rome.

Kusnawijaya, K. 1983. Peranan Cahaya Matahari dalam pendidikan IPA terhadap Lingkungan Rakyat, Jakarta.

Soeharsono. 1984. Biosintesa Karbohidrat. Biokimia II. University Gadjah Mada, Press.

Winarno, F. G. 1982. Kimia Pangan dan Gizi. Penerbit Gramedia, Jakarta.

Steel, R. G. D. dan Torrie, J. M. 1986. Principles and Prosedure of Statistic. Mc.Graw Hill Book.

Sudarmadji, S., Haryono, B., dan Suhardi. 1972. Prosedur Analisa untuk Bahan Makanan Pertanian. Badan Penerbitan Bagian Pengolahan Hasil Pertanian. Fakultas Teknologi Pertanian, UGM.

Wirahadikusumah, M. 1985. Biokimia; Metabolisme Energi, Karbohidrat, dan Lemak. Penerbit Hidup. CV. Genep aya Baru kerjasama dengan Pemerintah DKI. Jakarta. ITB Bandung. 